\title{
Accuracy of five electronic foramen locators with different operating systems: an ex vivo study
}

\author{
Bruno Carvalho de VASCONCELOS ${ }^{1}$, Michelli de Medeiros BUENO², Suyane Maria LUNA-CRUZ ${ }^{3}$, Marco Antonio \\ Hungaro DUARTE ${ }^{4}$, Carlos Augusto de Oliveira FERNANDES ${ }^{5}$
}

\author{
1- DDS, MSc, PhD, Sobral School of Dentistry, Federal University of Ceará and School of Pharmacy, Dentistry and Nursing, Federal University of Ceará, \\ Fortaleza, CE, Brazil. \\ 2- DDS, Brazilian Dental Association, Ceará Section, Fortaleza, CE, Brazil. \\ 3- DDS, MSc, Sobral School of Dentistry, Federal University of Ceará, Fortaleza, CE, Brazil. \\ 4- DDS, MSc, PhD, Associate Professor, Department of Operative Dentistry, Endodontics and Dental Materials, Bauru School of Dentistry, University of São \\ Paulo, Bauru, SP, Brazil \\ 5- DDS, MSc, PhD, School of Pharmacy, Dentistry and Nursing, Federal University of Ceará, Fortaleza, CE, Brazil.
}

Corresponding address: Bruno Carvalho de Vasconcelos - Universidade Federal do Ceará - Curso de Odontologia de Sobral - Departamento de Endodontia Rua Stanislau Frota s/n, Bloco da Tecnologia, Centro - 62010-560 - Sobral - CE - Brazil - Phone and Fax: +55 8836132603 - e-mail: bcv@ufc.br

Received: March 2, 2012 - Modification: January 6, 2013 - Accepted: February 9, 2013

\section{ABSTRACT}

\begin{abstract}
bjective: The aim of this study was to evaluate, ex vivo, the precision of five electronic root canal length measurement devices (ERCLMDs) with different operating systems: the Root ZX, Mini Apex Locator, Propex II, iPex, and RomiApex A-15, and the possible influence of the positioning of the instrument tips short of the apical foramen. Material and Methods: Forty-two mandibular bicuspids had their real canal lengths (RL) previously determined. Electronic measurements were performed $1.0 \mathrm{~mm}$ short of the apical foramen $(-1.0)$, followed by measurements at the apical foramen (0.0). The data resulting from the comparison of the ERCLMD measurements and the RL were evaluated by the Wilcoxon and Friedman tests at a significance level of 5\%. Results: Considering the measurements performed at 0.0 and -1.0 , the precision rates for the ERCLMDs were: $73.5 \%$ and $47.1 \%$ (Root ZX), 73.5\% and 55.9\% (Mini Apex Locator), 67.6\% and 41.1\% (Propex II), 61.7\% and $44.1 \%$ (iPex), and $79.4 \%$ and $44.1 \%$ (RomiApex A-15), respectively, considering \pm 0.5 $\mathrm{mm}$ of tolerance. Regarding the mean discrepancies, no differences were observed at 0.0; however, in the measurements at -1.0, the iPex, a multi-frequency ERCLMD, had significantly more discrepant readings short of the apical foramen than the other devices, except for the Propex II, which had intermediate results. When the ERCLMDs measurements at -1.0 were compared with those at 0.0, the Propex II, iPex and RomiApex A-15 presented significantly higher discrepancies in their readings. Conclusions: Under the conditions of the present study, all the ERCLMDs provided acceptable measurements at the 0.0 position. However, at the -1.0 position, the ERCLMDs had a lower precision, with statistically significant differences for the Propex II, iPex, and RomiApex A-15.
\end{abstract}

Key words: Endodontics. Tooth apex, anatomy \& histology. Odontometry methods. Dental equipment. Electric impedance.

\section{INTRODUCTION}

Precise root canal length determination using the apical constriction or the apical foramen (AF) as references is an extremely relevant factor for the success of endodontic treatments ${ }^{10,11,21,23}$. Electronic root canal length measurement devices (ERCLMDs) are considered efficient tools for this purpose ${ }^{12,15,18,26,28}$, achieving precision percentages upwards of $80 \%$ ex vivo $2,4,6,9,17-20,23-26$ and in
Vivo $^{8,23,27,29,30}$

Presently, the most widely used ERCLMD is the Root ZX (J. Morita, Tokyo, Japan), which simultaneously measures the impedance values at two different frequencies $(0.4$ and $8.0 \mathrm{kHz})$, then calculates their quotient value $4,15,17,23,25,26$. This device has been extensively evaluated, displaying precision rates greater than $90 \% 8,12,13,17,27,29$. Another popular ERCLMD is the Mini Apex Locator (SybronEndo, Glendora, USA), a compact device operating as a 
two frequency-based measurement system that emits an all-digital signal, which according to its manufacturers, leads to improved precision. Another ERCLMD, the iPex (NSK, Tochigi, Japan), based on a multi-frequency principle, was launched in 2008. However, little information is available regarding its technical specifications, aside from the fact that it utilizes two different signal frequencies. Both the Mini Apex Locator and the iPex have demonstrated satisfactory clinical results, despite the relative lack of information on their operating mechanisms, especially with regards to how these devices electronically interpret the impedance values obtained in the different frequencies during measurements within the canal $4,16,18,23,24,26$.

Recently launched in the market, the RomiApex A-15 (Romidan Ltd., Kyriat Ono, Israel) and the Propex II (Dentsply/Maillefer, Ballaigues, Switzerland), measure the working length by calculating the mean square root values of the impedance at two different frequencies ( 0.5 and $8.0 \mathrm{kHz}$ ), measured separately ${ }^{6,13,14}$. The devices compare the results obtained with reference values stored in its memories and then present the file positions. Thus, differing from most ERCLMDs, the RomiApex A-15 and the Propex II operate by detecting the energy of the signal, rather than its amplitude ${ }^{14}$. Although these devices seem promising, at the present there are no studies in the available literature evaluating the precision of the RomiApex A-15, both ex vivo and in vivo. As for the Propex II, at the present, its precision has only been evaluated ex vivo at the foramen level, with satisfactory results ${ }^{6,14}$. Despite being based on similar operating systems, these devices have different electronic components with distinct layouts, and the possible variations due to these differences are still unknown. Regardless of their operating mechanisms, ERCLMDs have been extensively evaluated, demonstrating satisfactory precision when files are inserted up to the $\mathrm{AF}^{4-}$ $7,9,12,13,15,19,26$. Nevertheless, some authors suggest the adoption of working length measurements short of the apical foramen in order to preserve the vitality of the foraminal tissues and possibly allow for the formation of a biological seal via the pulp tissue cells present in the cement canal2,24,27. However, recent studies show that the precision of some ERCLMDs is negatively affected in measurements short of the apical foramen, with significant variations in the mean distances to the working length in their measurements ${ }^{24,26}$. Nevertheless, the effects of this protocol of ERCLMD utilization are still unknown for some operating mechanisms employed by several of the devices currently in use, such as the Mini Apex Locator, the RomiApex A-15 and the Propex II.

With this in mind, the aim of the present study was to evaluate the performance of the Root ZX, the Mini Apex Locator, the Propex II, the iPex and the RomiApex A-15, all ERCLMDs with different operation systems, both at levels $1.0 \mathrm{~mm}$ short of the $A F(-1.0 \mathrm{~mm})$ and at the $A F(0.0 \mathrm{~mm})$.

\section{MATERIAL AND METHODS}

Forty-two single-rooted human mandibular bicuspids with completely formed roots and referred for extraction for orthodontic reasons were selected. This study was approved by the Ethics Committee of the Federal University of Ceará, Brazil under protocol number 099/11, prior to the sample collection. All the teeth were healthy, corresponded to Vertucci's type I root canal configurations and did not exhibit sharp curvatures.

The coronal access was performed using \#1012 and \#3081 high speed diamond burs (KG Sorensen, Barueri, Brazil) under constant irrigation. When absent, flat surfaces were created to serve as anatomical references for the rubber stops. The canals were initially explored with \#10 K-files (Dentsply/Maillefer, Ballaigues, Switzerland) to confirm the absence of anatomic alterations and the foraminal patency. Two teeth did not meet these criteria and were excluded from the study. The remaining specimens were numbered and had their real lengths ( $R L)$ determined with \#10 $\mathrm{K}$-files introduced into the canal until their tips were visualized at the apical foramen opening under 16x magnification using an operating microscope (DF Vasconcellos, São Paulo, Brazil). The distance between the tip of the file and the stop was measured by a digital caliper with \pm 0.01 $\mathrm{mm}$ resolution (FNCL; Worker Gage, Esteio, Brazil). The diameter of the K-file adjusted at the real canal lengths for each canal was also recorded.

The coronal and middle thirds were prepared using K3 30/.06 files (SybronEndo, Anaheim, USA) $5.0 \mathrm{~mm}$ short of the RL, under irrigation with $2.5 \%$ sodium hypochlorite. Next, the excess solution was removed but the canals remained moist. The root apices were embedded in alginate (Jeltrate II; Dentsply, Petrópolis, Brazil) previously mixed and immediately placed in a plastic container, along with the ERCLMD lip clip. Only five teeth were embedded per container, to ensure that the alginate remained fresh. All devices were used at full power and the measurements were conducted in triplicate by an operator blind to the RL. The first ERCLMD to be used was randomly determined, alternating the sequence employed for the remaining ERCLMDs. All the measurements were performed with files well fitted to the canal diameter, at the length appointed by each device. Initially, the file was inserted until the device displayed that the tip was at the position of $1.0 \mathrm{~mm}$ on the device display, and then the instrument was removed from the 
canal and measured. The measurements at the apical foramen level were conducted in the same manner, but the file was inserted until the "APEX" postion and/or 0.0 were displayed. Measurements were considered concluded only after 05 seconds of stability.

The mean values obtained were compared to the $\mathrm{RL}$ and $\mathrm{RL}-1.0 \mathrm{~mm}$ in order to calculate the mean error (discrepancy) of each device, in millimeters, at the two positions relative to the apical foramen. Negative and positive values were assigned for measurements under or over the previously determined RLs, respectively. Considering the nonparametric nature of the data presented by the Shapiro-Wilks goodness-of-fit test, the statistical analyses were carried out by the Wilcoxon test for the comparisons between both levels $(0.0 \mathrm{~mm}$ and $-1.0 \mathrm{~mm}$ ) for each ERCLMD measurement and by the Friedman test for comparisons among the ERCLMDs at the same level, both with a significance level established at 5\%.

\section{RESULTS}

The diameters of the root canals at the real canal length ranged between $150 \mu \mathrm{m}$ and $350 \mu \mathrm{m}$, presenting $250 \mu \mathrm{m}$ as the mean value.

Table 1 presents the mean error (absolute values of discrepancies), in millimeters, between the electronic measurements and the previously established RL and RL $-1.0 \mathrm{~mm}$. Comparison of the measurements at $0.0 \mathrm{~mm}$ and $-1.0 \mathrm{~mm}$, using the Propex II, the iPex, and the RomiApex A-15, presented statistically significant differences $(P<0.05)$, which was not observed for the Root ZX and the Mini Apex Locator $(P>0.05)$. Regardless of the ERCLMD utilized, statistically significant differences in the precision were also detected between the measurements taken at $0.0 \mathrm{~mm}$ and $-1.0 \mathrm{~mm}(P>0.05)$.

Tables 2 and 3 lists the distribution of measurements obtained from all devices at the 0.0 $\mathrm{mm}$ and $-1.0 \mathrm{~mm}$ levels, respectively. Considering the measurements performed at the $0.0 \mathrm{~mm}$ level, the occurrence of determinations beyond and at

Table 1- Distance $(\mathrm{mm})$ from device measurements to 0.0 and -1.0

\begin{tabular}{ccccccc}
\hline Device & & $\mathbf{0 . 0}$ & & & \multicolumn{1}{c}{$\mathbf{- 1 . 0}$} \\
& Mean* & SD & Mean Ranks & Mean $^{*}$ & SD & Mean Ranks \\
\hline Root ZX & $0.39^{\mathrm{a}, \mathrm{A}}$ & 0.29 & 0.43 & $0.61^{\mathrm{a}, \mathrm{A}}$ & 0.35 & 0.62 \\
Mini Apex Locator & $0.40^{\mathrm{a}, \mathrm{A}}$ & 0.32 & 0.50 & $0.61^{\mathrm{a}, \mathrm{A}}$ & 0.53 & 0.61 \\
\hline Propex II & $0.39^{\mathrm{a}, \mathrm{A}}$ & 0.30 & 0.50 & $0.80^{\mathrm{b}, \mathrm{AB}}$ & 0.41 & 0.81 \\
iPex & $0.47^{\mathrm{a}, \mathrm{A}}$ & 0.43 & 0.54 & $1.01^{\mathrm{b}, \mathrm{B}}$ & 0.55 & 1.01 \\
\hline RomiApex A-15 & $0.38^{\mathrm{a}, \mathrm{A}}$ & 0.27 & 0.39 & $0.68^{\mathrm{b}, \mathrm{A}}$ & 0.38 & 0.66 \\
\hline
\end{tabular}

* Mean error calculated in terms of absolute values of the determinations. SD= standard deviation

${ }^{a, b}$ Different superscript lower case letters indicate statistically significant differences between different positions in the same device according to the Wilconxon test $(P<.05)$

$A, B$ Different superscript upper case letters indicate statistically significant differences between different devices at the same position according to the Friedman test $(\mathrm{P}<.05)$

Table 2- File tip position relative to the apical foramen for measurements performed to 0.0

\begin{tabular}{|c|c|c|c|c|c|c|c|c|c|c|}
\hline \multirow{2}{*}{$\begin{array}{l}\text { Distance from } \\
\text { apical } \\
\text { foramen }(\mathrm{mm})\end{array}$} & \multicolumn{2}{|c|}{ Root ZX } & \multicolumn{2}{|c|}{$\begin{array}{l}\text { Mini Apex } \\
\text { Locator }\end{array}$} & \multicolumn{2}{|c|}{ Propex II } & \multicolumn{2}{|c|}{ iPex } & \multicolumn{2}{|c|}{ RomiApex A-15 } \\
\hline & $\mathbf{n}$ & $\%$ & $\mathbf{n}$ & $\%$ & $\mathbf{n}$ & $\%$ & $\mathbf{n}$ & $\%$ & $\mathbf{n}$ & $\%$ \\
\hline$<-1.01^{*}$ & 4 & 11.8 & 4 & 11.8 & 3 & 8.8 & 5 & 14.7 & 3 & 8.8 \\
\hline-1.0 to $-0.51^{*}$ & 3 & 8.8 & 5 & 14.7 & 8 & 23.5 & 7 & 20.6 & 3 & 8.8 \\
\hline-0.5 to $-0.01^{*}$ & 14 & 41.2 & 17 & 50.0 & 15 & 44.1 & 13 & 38.2 & 14 & 41.2 \\
\hline 0.00 & 2 & 5.9 & 1 & 2.9 & 3 & 8.8 & 3 & 8.8 & 3 & 8.8 \\
\hline 0.01 to 0.5 & 9 & 26.4 & 7 & 20.6 & 5 & 14.7 & 5 & 14.7 & 10 & 29.4 \\
\hline 0.51 to 1.0 & 2 & 5.9 & 0 & 0.0 & 0 & 0.0 & 1 & 2.9 & 1 & 2.9 \\
\hline$>1.01$ & 0 & 0.0 & 0 & 0.0 & 0 & 0.0 & 0 & 0.0 & 0 & 0.0 \\
\hline
\end{tabular}

${ }^{*}$ Negative value indicates file position short (or coronal) to the apical foramen 
Table 3- File tip position during measurements performed short of the apical foramen $(-1.0 \mathrm{~mm})$

\begin{tabular}{ccccccccccc}
\hline $\begin{array}{c}\text { Distance from } \\
\text { apical } \\
\text { foramen }(\mathbf{m m})\end{array}$ & \multicolumn{2}{c}{ Root ZX } & \multicolumn{2}{l}{$\begin{array}{l}\text { Mini Apex } \\
\text { Locator }\end{array}$} & \multicolumn{2}{l}{ Propex II } & & iPex & RomiApex A-15 \\
& $\mathbf{n}$ & $\%$ & $\mathbf{n}$ & $\%$ & $\mathbf{n}$ & $\%$ & $\mathbf{n}$ & $\%$ & $\mathbf{n}$ & $\%$ \\
\hline$<-2.01^{*}$ & 0 & 0.0 & 4 & 11.8 & 8 & 23.5 & 12 & 35.3 & 0 & 0 \\
\hline-2.0 to $-1.51^{*}$ & 3 & 8.8 & 5 & 14.7 & 6 & 17.6 & 2 & 5.9 & 3 & 8.8 \\
\hline-1.5 to $-1.01^{*}$ & 4 & 11.8 & 8 & 23.5 & 6 & 17.6 & 7 & 20.6 & 2 & 5.9 \\
\hline-1.00 & 1 & 2.9 & 2 & 5.9 & 2 & 5.9 & 0 & 0.0 & 0 & 0 \\
-0.99 to -0.50 & 11 & 32.4 & 9 & 26.5 & 6 & 17.6 & 8 & 23.5 & 13 & 38.2 \\
\hline-0.49 to 0.0 & 11 & 32.4 & 5 & 14.7 & 5 & 14.7 & 4 & 11.8 & 11 & 32.4 \\
$>0.01$ & 4 & 11.8 & 1 & 2.9 & 1 & 2.9 & 1 & 2.9 & 5 & 14.7 \\
\hline
\end{tabular}

*Negative value indicates file position short (or coronal) to the $-1.0 \mathrm{~mm}$ position

the apical foramen were determined at $32.9 \%$ and $5.9 \%$ (Root ZX), 20.6\% and 2.9\% (Mini Apex Locator), $14.7 \%$ and $8.8 \%$ (Propex II), $17.6 \%$ and $8.8 \%$ (iPex), and $32.3 \%$ and $8.8 \%$ (RomiApex A-15), respectively (Table 2 ).

\section{DISCUSSION}

Although the results from the ex vivo studies should not be simply extrapolated to a clinical setting, they still provide valuable information ${ }^{8}$. It would be difficult to use such a large number of devices with the same patient. Furthermore, ex vivo tests allow, as performed in the present study, the maintenance of all controlled conditions by using fresh alginate to simulate the periapical tissue conditions ${ }^{1}$, by maintaining the canals moist with a $\mathrm{NaOCl}$ solution during the acquirement of the measurements $8,26,28-30$, by verifying the patency of each canal ${ }^{14,28}$, pre-flaring ${ }^{3}$, and measuring the canals with well-fitted files $4,9,22,25$.

The values obtained for the measurements at the apical foramen level corroborate with previous studies, showing precision rates of approximately $90 \%$ (Root ZX at $88.2 \%$, Mini Apex Locator at $88.2 \%$, Propex II at $91.2 \%$, iPex at $85.3 \%$, and RomiApex A-15 at 91.2\%), assuming a tolerance margin of $\pm 1.0 \mathrm{~mm}^{19,23,26}$. Some authors, however, consider this margin to be excessive, overestimating the precision of the devices ${ }^{4,19,26,30}$. In fact, when the tolerance margin was set at $\pm 0.5 \mathrm{~mm}$, we observed marked reductions in the precision of all ERCLMDs (73.6\% for the Root ZX, $73.5 \%$ for the Mini Apex Locator, $67.6 \%$ for the Propex II, $61.7 \%$ for the iPex, and $79.4 \%$ for the RomiApex A-15), also reported by Pascon, et al. ${ }^{19}$ (2009) and Vasconcelos, et al. ${ }^{26}$ (2010). Thus, considering the risks of over-estimation of the precision of the devices, it seems more accurate to consider the tolerance margin of $\pm 0.5 \mathrm{~mm}$.
The mean error values showed that regardless of the operating system utilized, all the tested devices had a higher precision at the apical foramen level (0.0 mm), corroborating with previous evaluations for the Root ZX $(0.39 \pm 0.29 \mathrm{~mm})^{4,6,7,12,13,17,19,26}$, the Mini Apex Locator $(0.40 \pm 0.32 \mathrm{~mm})^{4,7}$, the Propex II $(0.39 \pm 0.30 \mathrm{~mm})^{6,12,13}$, and the iPex $(0.47 \pm 0.43$ $\mathrm{mm})^{16,23,26}$. As highlighted for the RomiApex A-15, no previous studies with a similar design evaluating its precision were found. However, our findings show that this device had the lowest mean error values among all the tested ERCLMDs (0.38 \pm 0.27 $\mathrm{mm}$ ) suggesting that systems based on the evaluation of the energy of the signal, instead of its amplitude, may result in extremely reliable measurements. Considering these values, special attention should be given to the fact that, in order to prevent the compensation between positive and negative readings, the mean error values have been calculated as its absolute values (modulus), representing the real error value produced by the devices.

For the measurements at the $-1.0 \mathrm{~mm}$ level, all devices suffered a reduction in their mean error values. Previous studies presented similar values for the Root ZX at this position 2,24,26, which despite presenting a slight increase in its mean error value (from $0.39 \mathrm{~mm}$ to $0.61 \mathrm{~mm}$ ), it can still be considered a precise device for measurements at the $-1.0 \mathrm{~mm}$ level. Similarly, the results for the iPex corroborate with a previous evaluation, where a great variation in the mean error values were found in the measurements conducted -1.0 $\mathrm{mm}$ short of the $\mathrm{AF}^{26}$. In the present study, the mean discrepancy of the iPex rose from $0.47 \mathrm{~mm}$ to $1.01 \mathrm{~mm}$, corresponding as the worst result among the tested devices $(P<0.05)$. For some reason, still unclear due to the relative lack of information regarding the operation of the iPex, it seems that the precision of this multi-frequency 
device is greatly affected when the instruments do not reach the AF. One possible hypothesis is that its operating system interprets the capacitance and the resistance separately at some instances, which would explain its loss of reliability when these factors are absent when determining the position of the instruments within the canals.

The other ERCLMDs, until now, had not been tested at positions short of the AF. The Mini Apex Locator, the Propex II, and the RomiApex A-15 also presented increases in their mean error values from $0.40 \mathrm{~mm}$ to $0.61 \mathrm{~mm}$, from $0.39 \mathrm{~mm}$ to $0.80 \mathrm{~mm}$, and from $0.38 \mathrm{~mm}$ to $0.68 \mathrm{~mm}$, respectively. The results provided by the Mini Apex Locator, despite the limited technical information available, suggest that its mechanism may be quite similar to that of the Root ZX, since the devices displayed analogous behavior at different levels. This was also observed in previous studies, where these devices were submitted to different root canal preparations or in the presence of different irrigating solutions $s^{4,7,9}$. The Propex II and the RomiApex A-15 presented statistical significant differences between their measurements at both levels $(0.0 \mathrm{~mm}$ and -1.0 $\mathrm{mm})(P<0.05)$. This behavior suggests that although these ERCLMDs rely on energy signals and not on their amplitude, their accuracy is reduced during complicating factors, such as not reaching the AF. This may be explained by the loss of resistance data, similarly to what might have occurred to the iPex.

The results demonstrated the importance of conducting electronic canal length measurements at the apical foramen level, with the file tip positioned either at the apical constriction or at the major AF, structures that cannot be differentiated clinically ${ }^{24,28}$. Nevertheless, the Mini Apex Locator, together with the Root ZX (which operates by calculating the impedance at two different frequencies) had a smaller loss of precision when the tip was positioned $1.0 \mathrm{~mm}$ short of the AF. On the other hand, the iPex (a multi-frequency device), the Propex II and the RomiApex A-15 (devices that operate by detecting the energy of the signal) suffered a significant loss of precision.

\section{CONCLUSION}

Under the conditions of the present study, all the ERCLMDs provided acceptable measurements at the position of 0.0 . However, at the -1.0 position, the ERCLMDs had a lower precision, with statistically significant differences for the Propex II, iPex, and RomiApex A-15.

\section{REFERENCES}

1- Baldi JV, Victorino FR, Bernardes RA, Moraes IG, Bramante CM, Garcia RB, et al. Influence of embedding media on the assessment of electronic apex locators. J Endod. 2007;33:476-9.

2- Bernardes RA, Duarte MAH, Vasconcelos BC, Moraes IG, Bernardineli N, Garcia RB, et al. Evaluation of precision length determination with 3 electronic apex locators: Root ZX, Elements Diagnostic Unit, RomiApex D-30. Oral Surg Oral Med Oral Pathol Oral Radiol Endod. 2007;104:e91-4.

3-Brito-Júnior M, Camilo CC, Moreira-Júnior G, Pecora JD, SousaNeto MD. Effect of pre-flaring and file size on the accuracy of two electronic apex locators. J Appl Oral Sci. 2012;20:538-43.

4- Camargo EJ, Zapata RO, Medeiros PL, Bramante CM, Bernardineli N, Garcia RG, et al. Influence of pre-flaring on the accuracy of length determination with four electronic apex locators. J Endod. 2009;35:1300-2.

5- Carvalho AL, Moura-Netto C, Moura AA, Marques MM, Davidowics $\mathrm{H}$. Accuracy of three electronic apex locators in the presence of different irrigating solutions. Braz Oral Res. 2010;24:394-8.

6- Cianconi L, Angotti V, Felici R, Conte G, Mancini M. Accuracy of three electronic apex locators compared with digital radiography: an ex vivo study. J Endod. 2010;36:2003-7.

7- D'Assunção FL, Albuquerque DS, Salazar-Silva JR, Santos VC, Sousa JC. Ex vivo evaluation of the accuracy and coefficient of repeatability of three electronic apex locators using a simple mounting model: a preliminary report. Int Endod J. 2010;43:26974.

8- Duran-Cidreu F, Stober E, Mercandé M, Vera J, Garcia M, Bueno $\mathrm{R}$, et al. Comparison of in vivo and in vitro readings when testing the accuracy of the Root ZX apex locator. J Endod. 2012;38;236-9. 9- Ebrahim AK, Wadachi R, Suda H. EX vivo evaluation of the ability of four different electronic apex locators to determine the working length in teeth with various foramen diameters. Aust Endod J. 2006;51:258-62.

10- Genç Ö, Alaçam T, Kayaoglu G. Evaluation of three instrumentation techniques at the precision of apical stop and apical sealing of obturation. J Appl Oral Sci. 2011;19:350-4.

11- Gomes-Filho JE, Hopp RN, Bernabé PF, Nery MJ, Otoboni-Filho JA, Dezan-Júnior E. Evaluation of the apical infiltration after root canal disruption and obturation. J Appl Oral Sci. 2008;16:345-9. 12- Jung IY, Yoon BH, Lee SJ. Comparison of the reliability of " 0.5 " and "APEX" mark measurements in two frequency-based electronic apex locators. J Endod. 2011;37:49-52.

13- Mancini M, Felici R, Conti G, Constantine M, Cianconi L. Accuracy of three electronic apex locators in anterior and posterior teeth: an ex vivo study. J Endod. 2011;37:684-7.

14- Miletic V, Beljic-Ivanovic, Ivanovic V. Clinical reproducibility of three electronic apex locators. Int Endod J. 2011;44:769-76. 15- Nekoofar MH, Ghandi MM, Hayes SJ, Dummer PMH. The fundamental operating principles of electronic root canal length measurement devices. Int Endod J. 2006;39:595-609.

16- Nelson-Filho P, Romualdo PC, Bonifacio KC, Leonardo MR, Silva RA, Silva LA. Accuracy of the iPex multi-frequency electronic apex locator in primary molar: an ex vivo study. Int Endod J. 2011;44:303-6.

17- Orosco FA, Bernardineli N, Garcia RB, Bramante CM, Duarte $\mathrm{MAH}$, Moraes IG. In vivo accuracy of conventional and digital radiographic methods in confirming root canal working length determination by Root ZX. J Appl Oral Sci. 2012;20:522-5.

18- Paludo L, Souza SL, Só MVR, Rosa RA, Vier-Pelisser FV, Duarte $\mathrm{MAH}$. An in vivo radiographic evaluation of the accuracy of Apex and iPex electronic Apex locators. Braz Dent J. 2012;23:54-8.

19- Pascon EA, Marrelli M, Congi O, Ciancio R, Miceli F, Versiani MA. An ex vivo comparison of working length determination by 3 electronic apex locators. Oral Surg Oral Med Oral Pathol Oral Radiol Endod. 2009;108:e147-51.

20- Renner D, Grazziotin-Soares R, Gavini G, Barletta FB. Influence of pulp condition on the accuracy of an electronic foramen locator in posterior teeth: an in vivo study. Braz Oral Res. 2012 26:106-11. 
21- Riccuci D, Langeland K. Apical limit of root canal instrumentation and obturation, part 2. Histological study. Int Endod J. 1998;31:394-409.

22- Schmitz MS, Santos R, Capelli A, Jacobovitz M, Sapanó JC, Pecora JD. Influence of cervical pre-flaring on determination of apical file size in mandibular molars: SEM analysis. Braz Dent J. 2008; $19: 245-51$

23- Stober EK, Duran-Sindreu F, Mercandé M, Vera J, Bueno R, Roig M. An evaluation of Root ZX and iPex apex locators: an in vivo study. J Endod. 2011;37:608-10.

24- Stool R, Urban-Klein B, Roggendorf MJ, Jablonski-Momenl A, Strauch, Frankenberger R. Effectiveness of four electronic apex locators to determine distance from apical foramen. Int Endod J. 2010;43:808-17.

25- Vasconcelos BC, Matos LA, Pinheiro-Júnior EC, Menezes AST, Vivacqua-Gomes N. Ex vivo accuracy of three electronic apex locators using different apical file sizes. Braz Dent J. 2012;23:199204.
26- Vasconcelos BC, Vale TM, Menezes AST, Pinheiro-Jr EC, Vivacqua-Gomes N, Bernardes RA, et al. An ex vivo comparison of root canal length determination by three electronic apex locators at positions short of the apical foramen. Oral Surg Oral Med Oral Pathol Oral Radiol Endod. 2010;110:e57-61.

27- Versiani MA, Santana BP, Caram CM, Pascon EA, Souza CJ, Biffi JC. EX vivo comparison of the accuracy of Root ZX II in detecting apical constriction using different meter readings. Oral Surg Oral Med Oral Pathol Oral Radiol Endod. 2009;108:e41-5.

28- Vyeira JP, Acosta J. Comparison of working length determination with radiographs and four electronic apex locators. Int Endod J. 2011;44:510-8.

29- Welk AR, Baumgartner JC, Marshall JG. An in vivo comparison of two frequency-based electronic apex locators. J Endod. 2003;29:497-500.

30- Wrbas KT, Ziegler AA, Altenburger MJ, Schirrmeister JF. In vivo comparison of working length determination with two electronic apex locators. Int Endod J. 2007;40:133-8. 